\title{
Interleaved Boost DC-DC Converter Using Delta-Sigma Modulation Suitable for Renewable Energy Applications
}

\author{
Farag S. Alargt, Ahmed S. Ashur, Mohamed A. Shrud, and Ahmad H. Kharaz
}

\begin{abstract}
It is generally accepted that interleaving techniques are efficient at reducing the input/output ripples and increasing the power output of boost converters operating in critical conduction mode.Pulse width modulation (PWM) is used to produce the switching pattern. But this technique causes large switching noise peaks at a multiple number of the carrierfrequency. This paper proposes Interleaved Boost DCDC suitablefor renewable energy applications. The proposed converterutilizes delta-sigma modulation to control pulse generator. A thorough and effective analysis of the converter is carried out in order to achieve the system stability and to improve the dynamic performance. The output response obtained by this method is very much improved compared to the conventional PWM method of control. Simulation results are provided to illustrate the advantages of the proposed converter and controller scheme. All the advantages of interleaving, such as higher efficiency and reduced ripple for voltage/current, are also achieved in the proposed converter.
\end{abstract}

Index Terms-DC-DC converters, interleaved boost converter, delta-sigma modulation, renewable energy.

\section{INTRODUCTION}

In recent years, renewable energy has become the fastest growing power sector in the world and becomes more widely adopted as an important source in the future, the commonly used renewable energy systems are hybrid power systems. hybrid power systems (HPS), as the name suggests, incorporate more than one type of power sources. Initially they were designed for powering remotely located telecommunication stations by integrating one or two renewable energy sources including wind turbine, photovoltaic cells and fuel cells with storage devices such as batteries [1], [2], Fig. 1 shows the general architecture of a hybrid power energy.

The major advantage of a hybrid system is that, when solar and wind power production is used together, the reliability of the system is enhanced. A additionally, the size of the battery storage can be reduced slightly as there is less reliance on one method of power production. Often, when there is no sun, there is plenty of wind. However, by combining these two intermittent sources the system's power transfer efficiency and reliability can be improved

Manuscript received January 14, 2014; revised April 3, 2014.

F. S. Alargtis is with The Centre for Solar Energy Research and Studies, Tripoli, Libya (e-mail: fareglarkt@hotmail.com).

A. S. Ashur is with the Department of Electrical and Electronic Engineering University of Tripoli, Tripoli, Libya (e-mail: a.ashur@hotmail.co.uk).

M. A. Shrud is with the Tripoli Institute of Electronic Technology, Tripoli, Libya (e-mail: mshrud@hotmail.com).

A. H. Kharaz is with the School of Engineering and Technology, Uinersity of Derby, DE22 3AW, UK (e-mail: a.kharaz@derby.ac.uk). significantly [3]. The conversion of non-conventional energy sources into useful DC or AC power for residential and industrial applications is becoming more popular and has been gaining a great deal of attention byresearchers in recent years. The main aim of the researchers, and will still be in the future, is to design and develop economic, highefficient, compact and light weight power conversion systems [4].

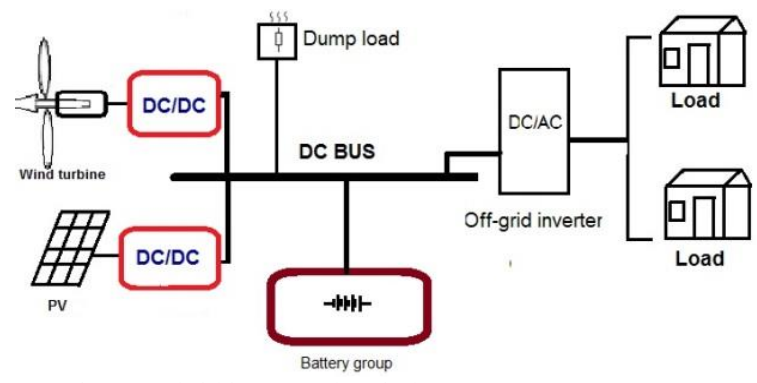

Fig. 1. Hybrid integrated (Wind-PV) power energy system.

Interleaved boost converter with PWM controlling is one such converter that can be used for these applications [1]. Pulse Width Modulation (PWM) signals have been widely employed in power electronic applications, but they have a drawback in that their power spectra tend to be concentrated around the switching frequency, causing a lot of harmonics. The harmonic spikes can have serious undesirable effects, such as acoustic noise, harmonic heating effects, mechanical vibration, switching losses in the semiconductor and electromagnetic interference [5].

Many types of PWM and soft switching techniques have been employed to solve these problems but there are a lot of new problems appearing like high switching losses and additional filters requiring complex software algorithms.

A digital controller has lower sensitivity to parameter variations compared to its analog counterpart; therefore digital solution is a better option when the controller demands high precision such as controlling multiphase converters [6]. Digital control can be more flexibly to meet the requirements of different applications, and the digital interface makes it easy to communicate with a power management system. Furthermore, through advanced digital control algorithms, it is possible to improve system performance in terms of efficiency and speed [7].

Most DC-DC converters use PWM controllers. However, rapid advances in power MOSFET devices have led to many researchers investigating the feasibility of $\Sigma \Delta$ modulators as controllers. The expected advantages over PWM controllers are as follows [7], [8]:

- Fast transient response

- High efficiency at low load

- Spread spectrum of switching noise 
- Can operate at higher switching frequency, and thus can use smaller $L$ and $C$.

In this paper a closed loop control $\Sigma \Delta$ modulation (SDM) has been proposed to generate modulation drives for threecell interleaved boost converter by using a closed-loop feedback scheme. The simulation study has been carried out with the help of MATLAB Simulink environment and the performance of the converter has been observed. A performance comparison between the conventional PWM technique and proposed method is included too.

In Section II and III respectively, the steps of the converter design and the interleaved multiphase boost converter are presented. The principles of $\Sigma \Delta$ modulation as control loop is introduced in Section IV. Simulation details and the results are reported and analyzed in Section V. A brief conclusion is drawn in Section VI.

\section{Design AND Modeling OF CONVERTER}

The circuit of the boost dc-dc converter is shown in Fig. 2 , its output voltage $V o$ is always higher than the input voltage Vi for steady-state operation. It 'boosts' the voltage to a higher level. The converter consists of an inductor $L$, a power MOSFET, a diode $D 1$, a filter capacitor $C$, and a load resistor $R_{L}$. The switch $S$ is turned on and off at the switching frequency $f_{s}=1 / T$ with the ON duty ratio $D=$ $t_{O N} / T$, where $t_{O N}$ is the time interval when the switch $\mathrm{S}$ is ON [8]-[10].

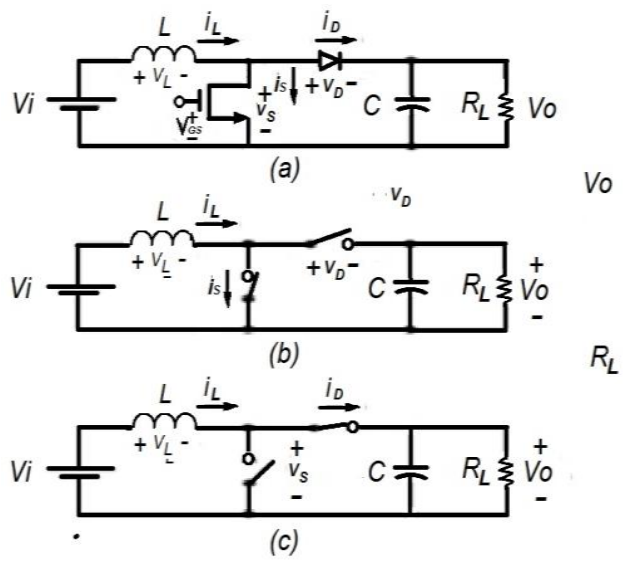

Fig. 2. Boost converter. (a) Circuit. (b) Equivalent circuit when the switch is ON and the diode is OFF. (c) Equivalent circuit when the switch is OFF and the diode is ON.

When the switch is closed, the source voltage is applied across the inductor and the rate of rise of inductor current is dependent on the source voltage $V i$ and inductance $L$. The differential equation describing this condition is [9]:

$$
L \frac{d i_{L}(t)}{d t}=V_{i}(t)
$$

If the source voltage remains constant, the rate of rise of inductor current is positive and remains fixed, so long as the inductor is not saturated. Then equation (1) can be expressed as:

$$
\frac{d i_{L}(t)}{d t}=\frac{V_{i}}{L}
$$

When the switch is open, the voltage across the inductor is:

$$
v_{L}=V_{i}-V_{o}
$$

Given that the output voltage is larger than the source voltage, the voltage across the inductor is negative and the rate of rise of inductor current, described by equation (4), is negative. Hence if the switch is held OFF for a time interval equal to $(1-D) T$, the change in inductor current can be computed as shown in equation (5)

$$
\begin{gathered}
\frac{d i_{L}(t)}{d t}=\frac{V_{i}-V_{o}}{L} \\
\Delta i_{L}(t)=\frac{V_{i}-V_{o}}{L} \times(1-D) T
\end{gathered}
$$

The change in the inductor current reflected by equation (5) is a negative value, since $V_{o}>V_{i}$. Since the net change in inductor current over a cycle period is zero when the response $i_{L}(t)$ is periodic, the sum of changes in inductor current expressed by (3) and (5) should be zero. That yields

$$
V_{o}=\frac{V_{i}}{1-D}
$$

The value of the inductance needed to ensure that the converter remains in Discontinuous Conduction Mode (DCM) of operation i.e. the inductor current is zero during part of the switching period and both semiconductor devices are OFF during some part of each cycle. The inductor value must be less than critical $L$, which can be determined as follow [11].

$$
L_{\text {critical }}=\frac{D \times V_{i} \times(1-D) T}{2 I_{o}}
$$

where,

$$
L<L_{\text {critical }}
$$

And

$$
I_{o}=\frac{P_{o}}{V_{o}}
$$

where $P_{o}$ is the output power.

The peak inductor current can becalculated as:

$$
I_{p k}=\frac{V_{i} D T}{L}
$$

The average inductor current can be found out by equating the power drawn from the source to the power delivered to the load resistor. Again the ripple in output voltage is ignored and it is assumed justifiably that the output voltage remains steady at its average value $V_{o}$. The power $P_{o}$ absorbed by load resistor is then: 


$$
P_{o}=\frac{\left(V_{O}\right)^{2}}{R}
$$

The average value of inductor current $I_{L}$ is also the average value of source current $I_{i}$, then:

$$
I_{\mathrm{L} ?}=\frac{\left(V_{O}\right)^{2}}{V_{i} \times R}
$$

Similarly, the output capacitance selection is also considered to make sure that output voltage ripple is within the desired boundary. The minimum capacitance required for certain output voltage ripple is given by [12],

$$
C_{\text {min }}=\frac{D T}{R \times V_{\text {ripple }}}
$$

However, the standard dc-dc converter with single structure is not practicable, due to the high current, and high power required, for renewable energy applications. Therefore, the power stage of the converter would have to be built in parallel for practical implementation. A common approach in the technical literature and industry practice is to use interleaved multi-phase technique instead of a single larger converter [9]. This approach will be discussed in the next section.

For low voltage/high current power converter, the usage of MOSFETs switching devices with low on-resistance is required for more efficient and practical power conversion. The inductors and capacitors play important roles in the design of the power converter. Inductor is an energy storage element while the capacitor is the main buffer for absorbing the ripple current generated by the switching action of the power stage. Components were calculated from equations above with $V_{i}=12 \mathrm{~V}, V_{o}=48 \mathrm{~V}$, and $P_{o}=1300 \mathrm{~W}$.

\section{INTERLEAVED MULTIPHASE SWITCHING OF DC-TO-DC CONVERTER}

To realize power conversion by a simple system configuration, a multi-cell boost converter topology designed for DCM operation is employed. Fig. 3 shows the developed Simulink diagram of three-cell interleaved boost converter with SDM control loop.

The three-cell interleaved boost converter is connected in parallel to a common output capacitor and sharing a common load with the associated control system. In this interleaved three-cell dc/dc converter architecture, the cells are switched with the same duty ratio, but with a relative phase shift or time interleaved of $120^{\circ}$ introduced between each cell in order to reduce the magnitude of the ripple at the output port of the converter. The overall output current is achieved by the summation of the output currents of the cells. With the phase shift of $120^{\circ}$, the output of the converter is found to be continuous. Due to the equal sharing of the load current between cells, the overwork on the semiconductor switches is reduced and thereby reliability is improved [11].

Another advantage is the ability to operate the converter when a failure occurs in one cell as well as the possibility to add new cells to the converter with minimum efforts. The output capacitor is another important element, which may reduce the system cost in multi-phase converter system and is needed to keep the output voltage ripple $V_{\text {ripple }}$ within the allowable output voltage range [9].

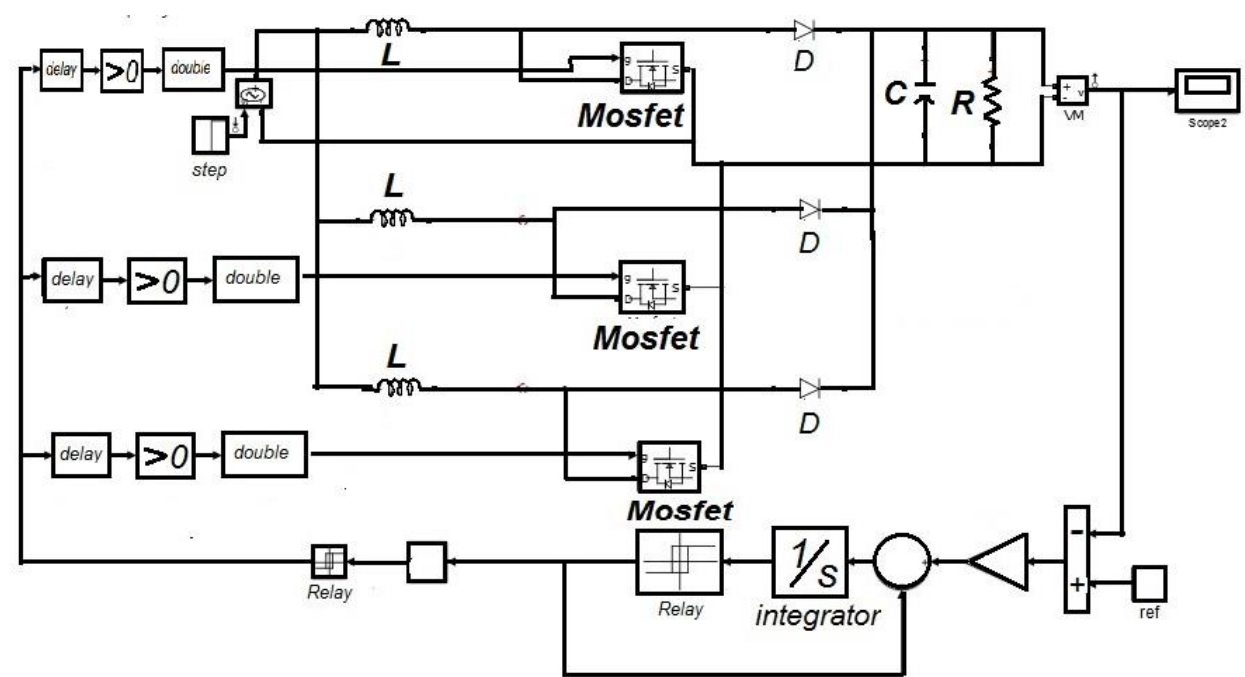

Fig. 3. Simulink implementation of the interleaved three-phase boost converter circuit with SDM control loop.

\section{IV. $\Sigma \Delta$ CONTROL LOOP}

Sigma-Delta modulation $(\Sigma-\Delta \mathrm{M})$ is a technique for converting analog signals into digital data. $\Sigma-\Delta \mathrm{M}$ is an improvement of an older Delta modulation (DM or $\Delta$ modulation). DM is an analog-to-digital modulation technique used mainly for a wide variety of applications, including digital telephony over the Internet, digital wireless and $4^{\text {th }}$ generation mobile communications [13].
The SDM consists of an integrator and a quantizer in a feedback loop, as shown in Fig. 4. The quantizer considered here is a 1-bit quantizer type with its output is either +1 or 1 , and its input is the integral of the difference between the input and the quantized output. That is, the quantization error. As an effect of the feedback loop, the average value at the integrator input is brought to zero. An equivalent discrete time model for the SDM can be obtained by using the following difference equation [13]: 


$$
\begin{gathered}
u(n+1)=x(n)-y(n)+u(n) \\
y(n)=+1 \text { if } u(n) \geq 0 \\
-1 \text { if } u(n)<0
\end{gathered}
$$

where $x(n), u(n)$, and $y(n)$ denote the input signal, the integrator state, and the output of the quantizer, respectively. And

$$
e(n)=y(n)-u(n)
$$

With the equation (13) and (15), the output equation can be obtained as

$$
y(n+1)=x(n)+e(n+1)-e(n)
$$

The output equation in (4) can be rewritten byz-transform as

$$
y(z)=z^{-1} x(z)+e(z)\left(1-z^{-1}\right)
$$

Using the equation (17), the discrete-time linear systemmodel of the SDM is obtained.

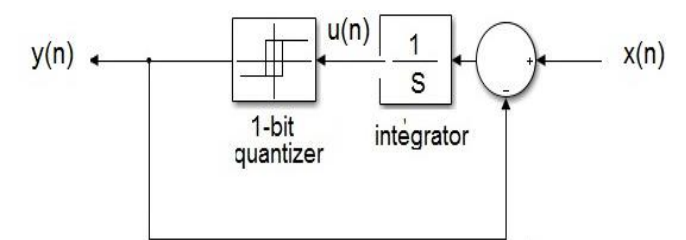

Fig. 4. First order delta-sigma modulation circuit implementation.

Thus the signal transfer function is given by $z^{-1}$. The signal is unaffected and only delayed by one sample. The noise transfer function is $1-z^{-1}$, which pushes the noise to high frequencies.

In Fig. 4, we assume that the comparator threshold value is 1 and the input signal $x$. The input to the modulator is integrated, thus creating a ramp with a slope proportional to the constant input. At time $n=1,2, \ldots, m$, the ramp sample $u(n)$ is compared to the threshold value of 1 and the output $y(n)=1$ if $u(n)>1$, otherwise $y(n)=0$. If $y(n)=1$, a one is subtracted from the ramp value. Thus in effect the modulator is predicting the ramp value by counting the number of ones and subtracting off its prediction via the feedback loop. Fig. 5 shows the output waveforms of the SDM circuit when apply sine wave as an input to illustrate the basis of its work.

In DC-DC converters, the aim is to regulate the output voltage of the converter $V_{o}$ across the load resistance $R_{L}$ to match a precise stable reference voltage $V_{\text {ref. }}$. This is achieved by subtracting the desired reference voltage $V_{\text {ref }}$ from the sensed output Voltage $V_{o}$ of the converter. The voltage-error thus obtained is passed through a delta-sigma modulation, this error is integrated, and when the integral of the error exceeds the limits, the output changes state. The output signal from the sigma delta modulation circuit is the switching control signal, which represents a sequence of pulses that drives the semiconductor switches, waveforms in every stage are shown in Fig. 6.
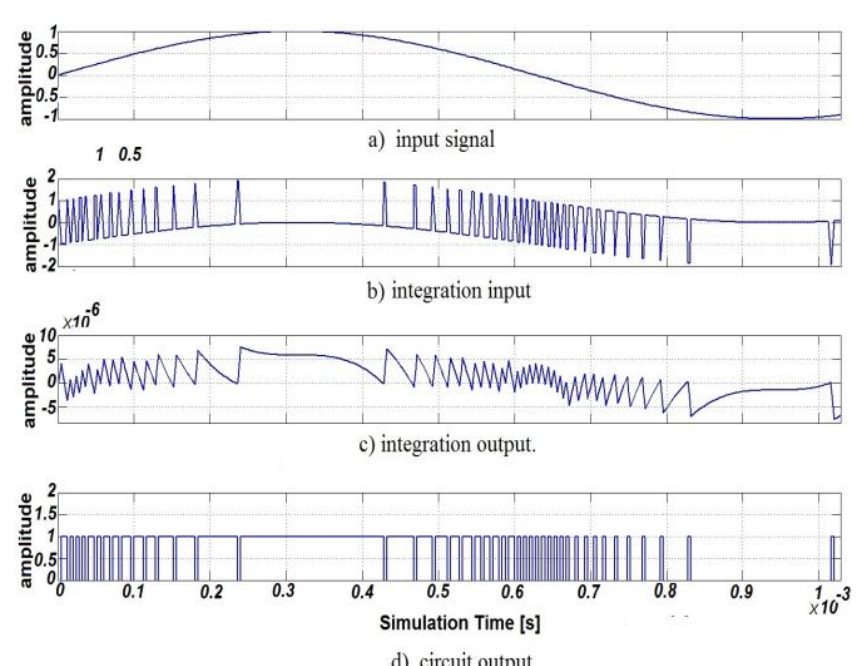

Fig. 5. Waveform through the $\Sigma \Delta$ modulation loop ,a)input signal ,b) integration input ,c) integration output and d) circuit output.
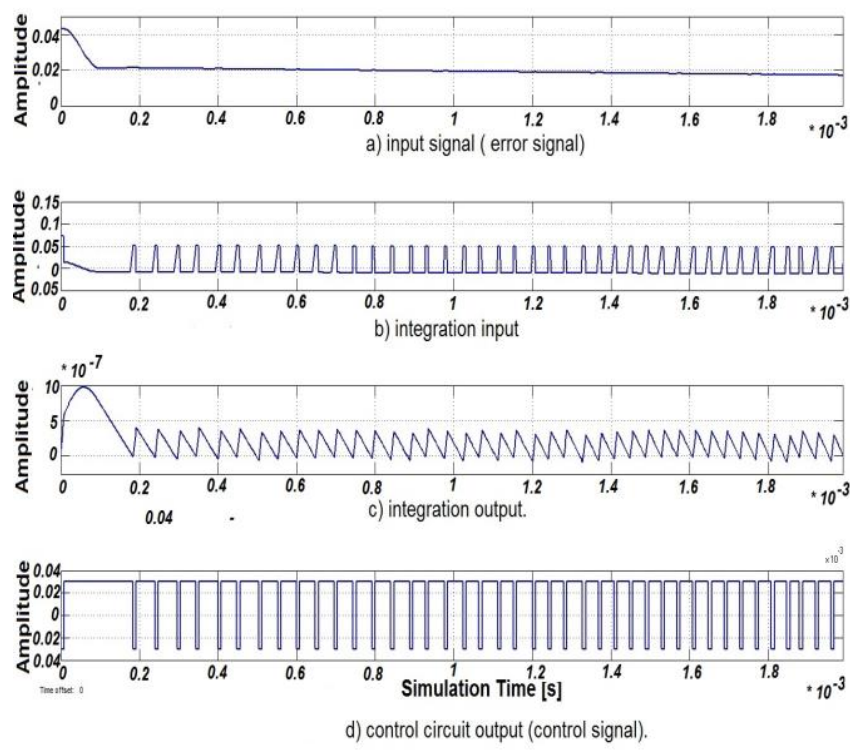

Fig. 6. Waveform through the $\Sigma \Delta$ modulation loop, a) input signal (error signal), b) integration input, c) integration output and d) circuit output (control signal).

The proposed converter necessitates a phase-shift of $120^{\circ}$ between the cells to generate the three-switching control signal which are used to drive the tree active MOSFET switching devices of the converter system. Fig. 7 and Fig. 8 show the implementation of the three phase interleaving circuit in Simulink and the three phase control signal waveforms respectively.

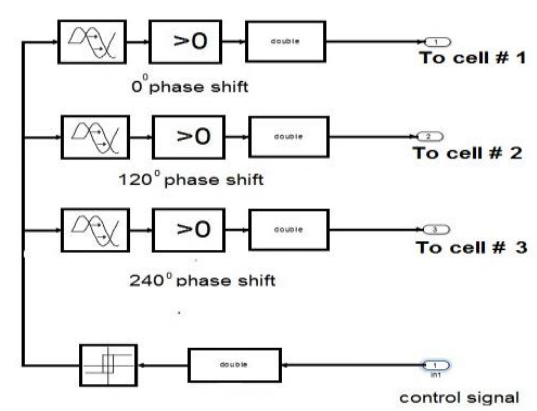

Fig. 7. Three phases of interleaving in Simulink. 

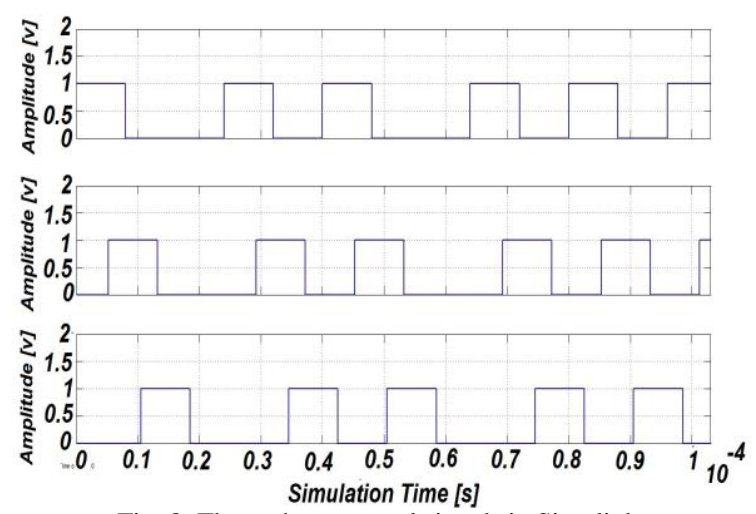

Fig. 8. Three phase control signals in Simulink.

\section{Simulation AND Results}

The complete model of the Simulink implementation of the internal structure of the interleaved three-phase boost converter system is shown in Fig. 9. The converter system is divided into three main parts; the three cell boost converter, the SDM circuit and the phase shift circuit. The multi-phase converter has been simulated to obtain the necessary waveforms that describe the converter system operation under steady-state and transient conditions, using the design parameters tabulated in Table I.

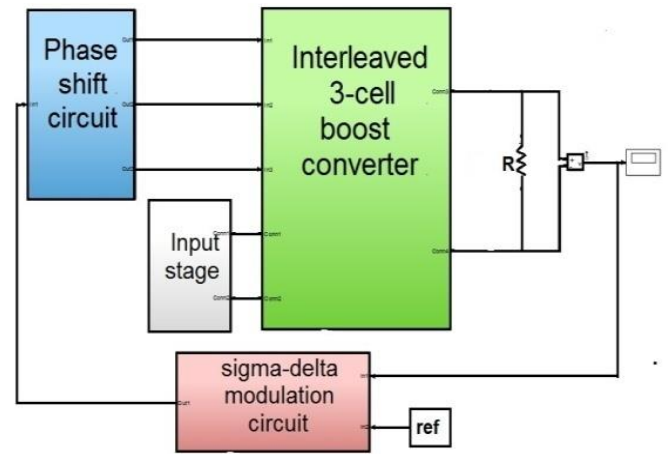

Fig. 9. Simulink schematic diagram illustrating the implementation of interleaved three-phase boost converter circuit with a SDM circuit.

TABLE I: PARAMETERS OF THE CONVERTER

\begin{tabular}{lccc}
\hline \hline \multicolumn{1}{c}{ parameter } & symbol & value & unit \\
\hline \hline Input voltage & $V_{i}$ & 12 & $\mathrm{~V}$ \\
Output voltage & $V_{o}$ & 48 & $\mathrm{~V}$ \\
Number of phases & $N$ & 3 & - \\
Inductor value & $L$ & .882 & $\mu \mathrm{H}$ \\
Capacitor value & $C$ & 3.5 & $\mathrm{mF}$ \\
Load resistance & $R_{L}$ & 1.764 & $\mathrm{ohm}$ \\
Sampling frequency & $F_{c}$ & 125 & $\mathrm{kHz}$ \\
\hline
\end{tabular}

The first step in the analysis of the multi-phase interleaved converter system is to investigate the effectiveness of ripple cancellation, it can be seen from Fig. 10 , that the ripple of output voltage is $21.6 \mathrm{mV}$, and the ripple of the total inductor current of the converter is $11.8 \mathrm{~mA}$.

Fig. 11 shows the steady-state waveforms of the individual I/O cell currents, the simulated results show that the curves of the individual cell currents for the input are rises to $108.84 \mathrm{~A}$ during each switching period and goes through an interval in the discontinuous conduction mode.

Fig. 12 shows the total output current and the output voltage of the converter system, the operation of the power converter system is stable and accurate. The converter is able to respond and produce the desired stable output voltage and deliver the required total output current to the load with very low ripple.

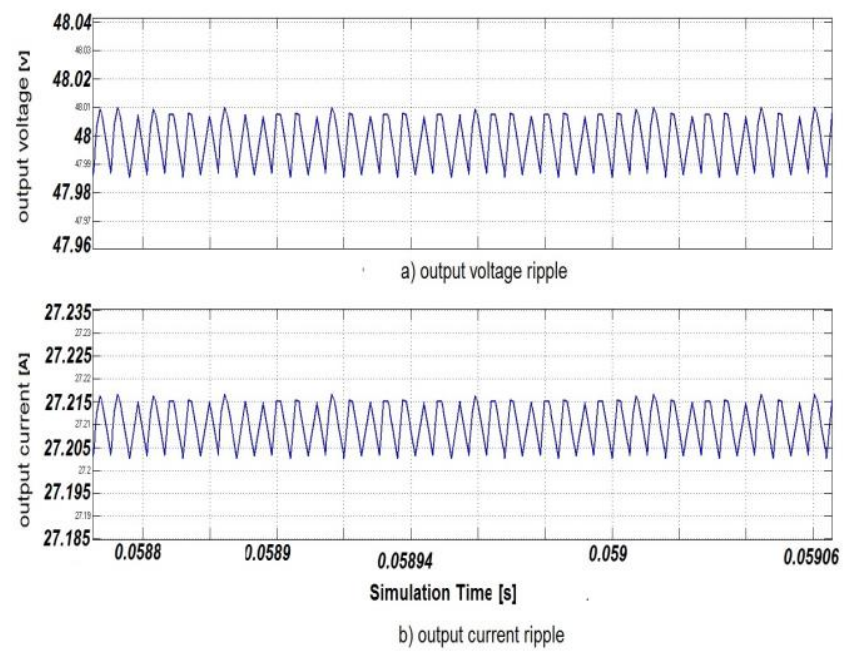

Fig. 10. Output Ripples. a) output voltage ripples , b) output current ripples.
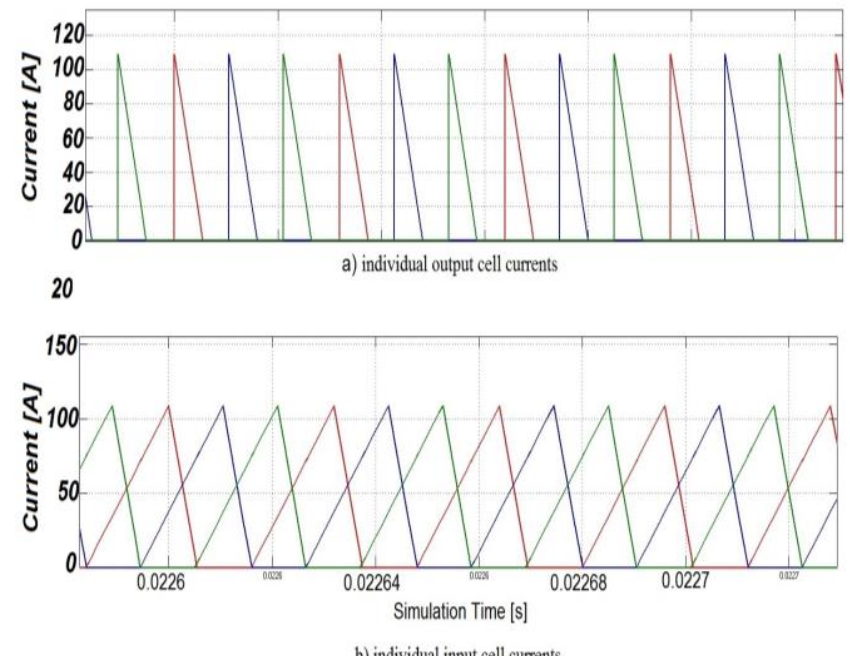

Fig. 11. The individual cell currents waveform. a) output cell currents , b) input cell currents.
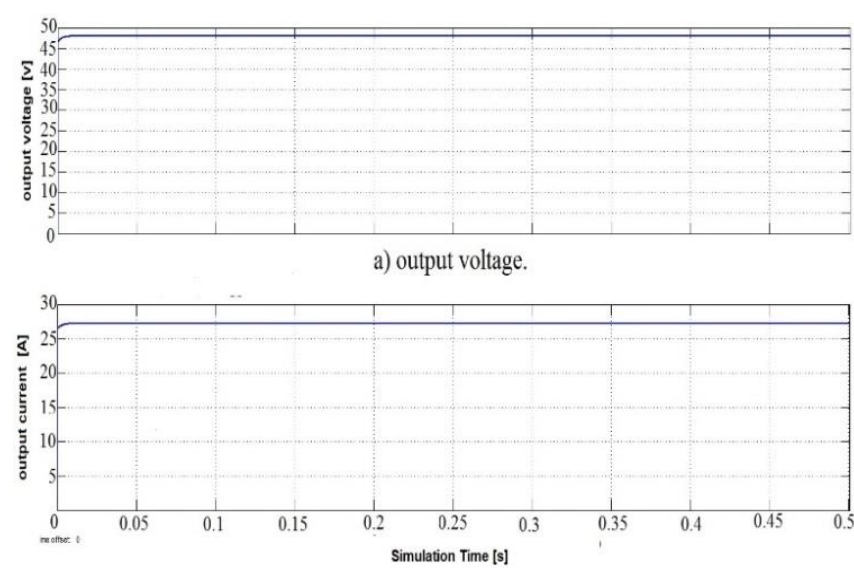

b) output current.

Fig. 12. The total output of the converter, a) output voltage, b) output current.

In [11] interleaved boost converter with PWM / PID controller technique was proposed to use in automotive application, Table II give a summary of the converter 
parameters and Fig. 13 shows the Simulink implementation of this converter with the PWM technique.

TABLE II: PARAMETERS OF THE CONVERTER [11]

\begin{tabular}{lccc}
\hline \multicolumn{1}{c}{ parameter } & symbol & value & unit \\
\hline \hline Input voltage & $V_{i}$ & 14 & $\mathrm{~V}$ \\
Output voltage & $V_{o}$ & 42 & $\mathrm{~V}$ \\
Number of phases & $N$ & 3 & - \\
Inductor value & $L$ & 0.885 & $\mu \mathrm{H}$ \\
Capacitor value & $C$ & 3.9 & $\mathrm{mF}$ \\
Load resistance & $R_{L}$ & 1.764 & $\mathrm{ohm}$ \\
Switching frequency & $f_{s}$ & 100 & $\mathrm{kHz}$ \\
\hline
\end{tabular}

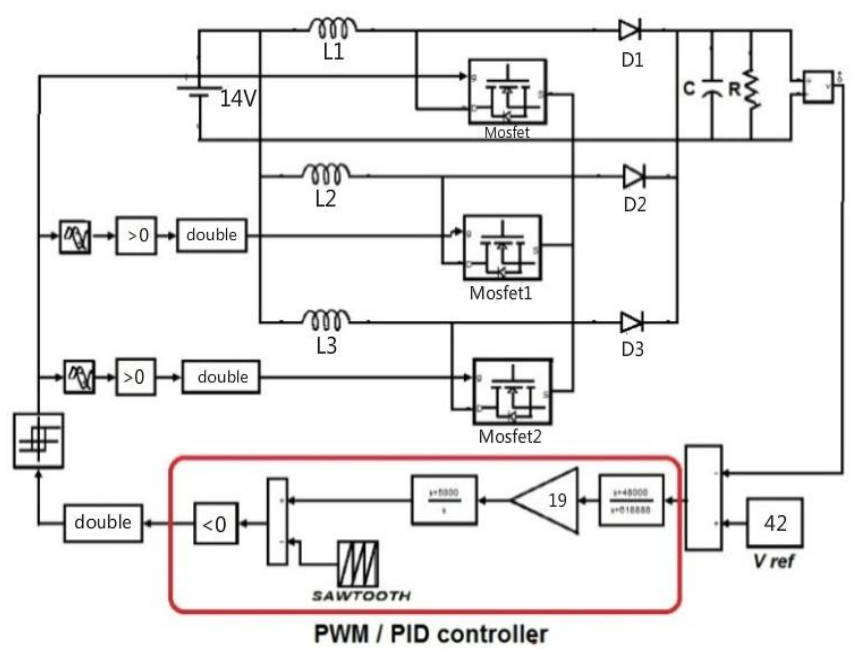

Fig. 13. The Simulink implementation of the converter with the PWM / PID technique used in [5].

The feedback loop in [11] was replaced by the new proposed $\Sigma \Delta$ loop to make performance comparison between the PWM / PID and $\Sigma \Delta$ modulation method, Fig. 14 and Fig. 15 show the comparison results between the PWM with PID controller and the proposed $\Sigma \Delta$ control loop the results show that the converter with $\Sigma \Delta$ control loop has very fast response and low ripples, Table III, summarizes the results of the comparison between the two methods.

TABLE III: SUMMARIZES THE RESULTS OF THE COMPARISON BETWEEN THE TWO METHODS

\begin{tabular}{ccccc}
\hline \hline parameters & $\begin{array}{c}\text { Output } \\
\mathrm{V}_{\text {ripple }}[\mathrm{v}]\end{array}$ & $\begin{array}{c}\text { output } \\
\mathrm{I}_{\text {ripple }}[\mathrm{A}]\end{array}$ & $\begin{array}{c}\text { settling } \\
\text { Time [s] }\end{array}$ & $\begin{array}{c}\text { voltage } \\
\text { overshoot } \\
{[\mathrm{v}]}\end{array}$ \\
\hline \hline $\begin{array}{c}\text { PWM / PID } \\
\text { method[5] }\end{array}$ & 0.0158 & 0.0087 & $12 \mathrm{E}-04$ & 1.1893 \\
$\begin{array}{c}\text { Proposed } \Sigma \Delta \\
\text { method }\end{array}$ & 0.0066 & 0.0037 & $1.5301 \mathrm{E}-04$ & 0.0168 \\
\hline \hline
\end{tabular}

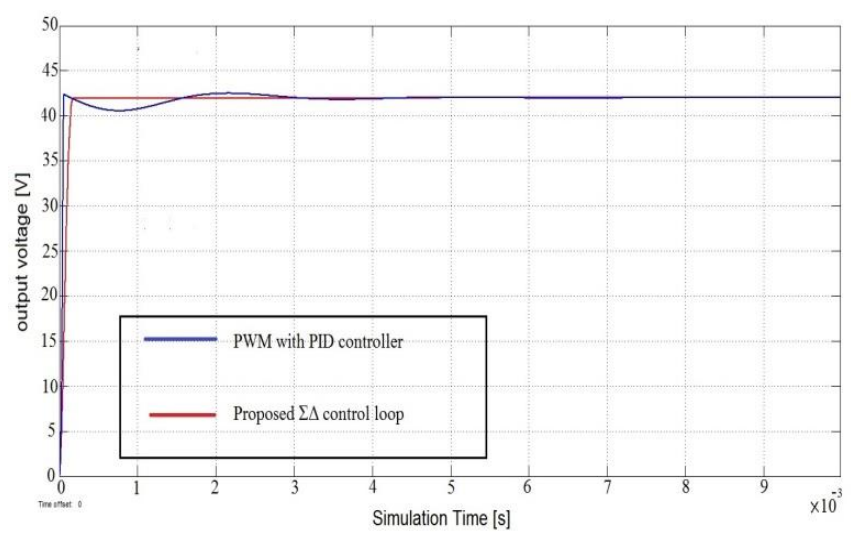

Fig. 14. Comparison of output voltage response between PWM with PID controller and the proposed $\Sigma \Delta$ control loop.

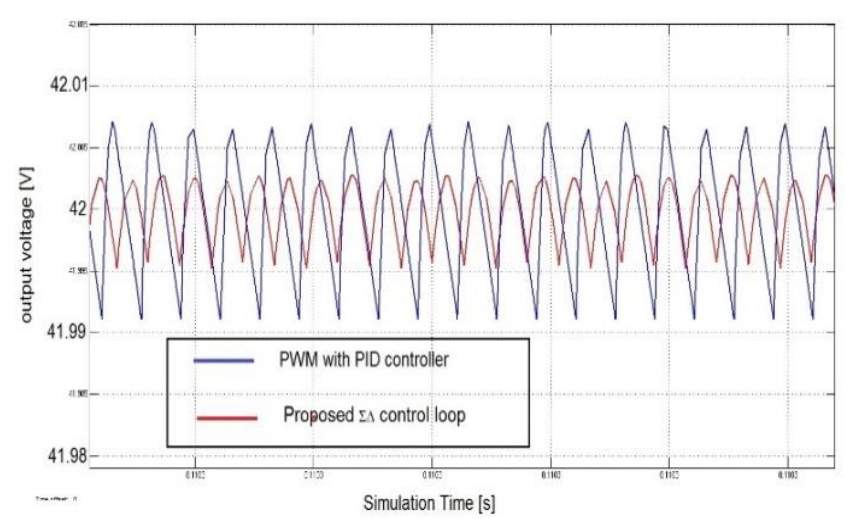

Fig. 15. Comparison of output voltage ripples between PWM with PID controller and the proposed $\Sigma \Delta$ control loop.

\section{CONCLUSION}

This paper has proposed using $\Sigma \Delta$ modulator as controllers for three-phase DC-DC boost converter to apply in renewable energy applications. The booster exibits a small size and the overall power consumption is very low. All the advantages of using $\Sigma \Delta$ modulation in DC-DC converters such as reducing conducted EMI and the harmonic spikes have been also achieved in the proposed technique. Simulation results show that $\Sigma \Delta$ modulation loop can produce an excellent output response and ripples cancelation. The simulation results also show that the proposed controller technique has a significantly improved performance over conventional PWM controller.

\section{REFERENCES}

[1] J. S. AnuRahavi, T. Kanagapriya, and R. Seyezhai, "Design and analysis of interleaved boost converter for renewable energy source," in Proc. International Conference on Energy Efficient Technologies for Sustainability (ICEETS), 2012 , pp. 447-451.

[2] X. Y. Xu and L. Z. Zhu, "A DSP based controller for high-power interleaved boost converters," APEC'03, vol. 1, pp. 327-333.

[3] B. M. Shagar et al., "Design of DC-DC converter for hybrid wind solar energy system," in Proc. Int. Conf. on Computing, Electronics and Electrical Technologies, 2012, pp. 429-435.

[4] S. Nigam, P. Baul, and S. K. Sharma, "Soft switched low stress high efficient ZVT PWM DC-DC converter for renewable energy applications," in Proc. International Conference on Energy Efficient Technologies for Sustainability, 2013, pp. 1189-1194.

[5] S. H. Kim, W. Choi, S. Choi, and K. B. Lee, "Combined dithered sigma-delta modulation based random PWM switching scheme," Journal of Power Electronics, vol. 9, no. 5, pp. 667-678, 2009.

[6] N. Kong et al., "Off-time prediction in digital constant on-time modulation for DC-DC converters," in Proc. IEEE International Symposium on Circuits and Systems, 2008, pp. 3270-3273.

[7] H. Gao and L. Xing, "DC-DC converter with continuous-time feedforward sigma-delta modulator control," in Proc. IEEE Asia Pacific Conference on Circuits and Systems, 2012, pp. 65-68.

[8] M. H. Rashid, Power Electronics Handbook, Academic Press Series in Engineering, 2001.

[9] A. Shrud et al., "Analysis and simulation of automotive interleaved buck converter," World Academy of Science, Engineering and Technology, vol. 63, 2010.

[10] On Semiconductor, WITCHMODE ${ }^{\mathrm{TM}}$ Power Supplies Reference Manual and Design Guide, 2007.

[11] F. S. Alargt and A. S. Ashur, "Analysis and simulation of interleaved boost converter for automotive applications," in Proc. the 1st International Conference on Electrical and Computer Engineering, 2013.

[12] S. K. Kumaran and K. R. Santha, "DSP control of DC/DC boost converter for fuel cell based hybrid electric vehicle," in Proc. IEEE International Conference On Advances In Engineering, Science And Management, 2012.

[13] R. Schreier, Understanding Delta-Sigma Data Converters, New York: Wiley-IEEE Press, 2004. 
Farag S. Alargt was born in Zliten, Libya, in 1982. $\mathrm{He}$ received the B.S. degree in electrical and electronic engineering from Almergb University, Alkhoms, Libya, in 2007. He is currently working toward the M.S. degree in electrical engineering in Tripoli University, Tripoli, Libya.

Since 2012, he has been a Researcher at Centre for Solar Energy Research and Studies. His research interests include modeling and control of switching $\mathrm{dc}-\mathrm{dc}$ converters and renewable energy technology.

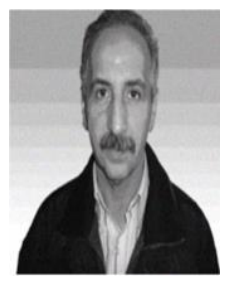

Ahmed Said Ashur obtained his BSc from the University of Al-Fatah in 1975, his MSc from the Southern California University (USC) in 1981, and his $\mathrm{PhD}$ from University of Nottingham in 1996. He is a faculty member at the University of Tripoli since 1981. His area of interest is digital signal processing algorithms, systems, applications, and communications. He has more than 20 publications in reputable journals, and international conferences.

Ahmad Kharaz attended Cardiff University, UK, where he received a BSc (Hons) in Electrical and Electronic Engineering. He began his career in industry as an electronic design engineer where he introduced a number of new products to the market in control, instrumentation and biofeedback. He then attended Brunel University, London, UK, where he received his MSc and $\mathrm{PhD}$ in Industrial Measurement Systems. Following that he worked at the Open University headquarters in teaching and research for five years. He has been working at Derby University since 1999. In 2007 He became a reader in intelligent instrumentation. His specialist fields are intelligent instrumentations and control, metrology, electrical power quality and optical fibre sensors. He authored many publications in reputable journals, and international conferences. 